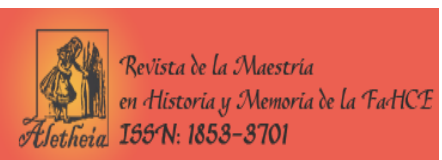

\title{
La estética de la acción y el Cordobazo: el caso de la revista Sobre
}

Aesthetics of Action and the Cordobazo: the case of the journal Sobre

\section{Lucas Rubinich}

Facultad de Ciencias Sociales, Universidad de Buenos Aires, Argentina

rubinich@retina.ar

\section{Resumen:}

La revista "Sobre. La cultura de la liberación”, es una publicación que expresa a un grupo de la vanguardia artística argentina, en su momento de más intensa radicalidad política. Aparece inmediatamente después de ocurrido el Cordobazo. A través del análisis de Sobre, que en su forma, y en su manera de distribución es pensada como una herramienta que incita a la acción, es probable identificar algunos elementos que explican tanto la empatía conceptual de esta vanguardia artística con estos hechos, como el desencuentro, que se producirá con la vanguardia política.

Palabras clave: Vanguardia artística, Vanguardia política, Efervescencia social.

\section{AbstraCt:}

The journal "Sobre. La cultura de la liberación” represents a group of the artistic avant-garde in Argentina during an intense period marked by political radicalism. The journal had been published immediately after the Cordobazo. Analyzing Sobre, whose design and distribution is devised as a tool to spark action, I identify some elements that explain the conceptual empathy of this artistic avant-garde and those events as well as the clash with the political avant-garde.

KEYworDS: Artistic Avant-Garde, Political Avant-Garde, Social Effervescence.

\section{I}

A un mes de ocurrido el movimiento de rebelión popular conocido como el Cordobazo en el que participaron activamente mayoritarios sectores de la clase obrera organizada y el movimiento estudiantil universitario, aparece en Buenos Aires una revista llamada "Sobre. La cultura de la liberación", de la cual se publicarán dos números. El $\mathrm{N}^{\circ} 1$ en julio de $1969 \mathrm{y}$ el $\mathrm{N}^{\circ} 2$, probablemente en setiembre del mismo año (Sobre, 1969). La revista tiene una forma no convencional, es efectivamente un sobre de papel madera con textos y afiches en su interior, y es la expresión más fuerte de un proceso de experimentación estética y radicalización política ocurrido en una zona dinámica del campo de las modernas artes plásticas. La propuesta explicitada en el manifiesto que está en el dorso del sobre (el lado que sería la contratapa) es que la revista sea un recurso de debate dirigido a la implicación en la acción: "A SOBRE no lo queremos intacto./queremos que se deshaga/que se gaste,/Que se arroje como una granada/QUE SEA UN ARMA/ SOBRE no es solo para leer:/es para usar/No lo guarde en un cajón ni lo coleccione en su biblioteca." (Sobre, 1969)

Si bien la significación en el momento puede ser mínima y acotada a espacios de lo que Bourdieu llamará el campo restringido (Bourdieu, 2008), es un indicador privilegiado, en principio, para acercarse al proceso de radicalización de las generaciones jóvenes con voluntad experimental en el campo de lo que en ese momento se llamaba las artes plásticas; pero, fundamentalmente, para pensar cómo el Cordobazo, en tanto acontecimiento crítico significativo en términos políticos y político culturales, actuó potenciando de distintas maneras otros espacios ya habilitados a desconfiar y a cuestionar el orden. Y que, en este caso específico, influyó afianzando la radicalidad de una estética que al incorporar la acción como elemento constitutivo de la obra artística (si se quiere la acción con voluntad problematizadora) no pudo hacer otra cosa que intensificar sus propuestas. La revista expresa el momento de mayor intensificación de esa perspectiva, y a la vez el último 
intento por diseñar un espacio de contención que los límites de ese campo artístico (a diferencia del cine y la literatura) no permitieron conformar.

\section{II}

El manifiesto editorial de la revista Sobre está firmado por tres colectivos: Grupo de agitación y propaganda, Grupo cine liberación, y Grupo de psicólogos por la liberación. Estas denominaciones se relacionan más con la idea de afirmarse en experiencias colectivas que con la existencia real de cada uno de esos grupos. El que tenía existencia fuerte y posibilidades reales de continuidad por sus relaciones internacionales es el Grupo cine liberación, los otros dos probablemente sean producto de esa voluntad de otorgarle a la experiencia un tono colectivo. En verdad se trataba fundamentalmente de cuatro personas que tenían el papel más activo: centralmente Roberto Jacoby, uno de los jóvenes que en 1966 habían realizado la obra que se llamó "La primera obra de los medios de comunicación" o "el antihappening", y que atrajo la atención de referentes de la cultura nacional como el joven y prestigioso sociólogo Eliseo Verón, e internacionales, como el mexicano Octavio Paz (Masotta, 1967). Jacoby es discípulo de una figura clave de la nueva izquierda que es Oscar Masotta (Masotta, 1967, 1969, 2004), y será participante activo de casi todas las experiencias disruptivas protagonizadas durante 1968 por artistas prestigiosos de la nueva generación que podrían denominarse los rebeldes del Di Tella, muchos de los cuales participarán a fines de 1968 de la experiencia de arte colectivo Tucumán Arde (Longoni y Mestman, 2008 y Longoni, 2014). Otro de los participantes es Octavio Getino, co-realizador de La hora de los hornos, del grupo cine liberación (Oubiña, 2016), también la poeta Beatriz Balvé que había participado de Tucumán Arde y con lazos con el Centro de investigación en Ciencias Sociales (CICSO), (Santella, 2000) y el médico psiquiatra Antonio Caparrós.

Lo que posibilita el encuentro es la sensibilidad política que se radicaliza, pero también en el caso de las dos experiencias artísticas (trayectoria de Roberto Jacoby y la experiencia de Getino en el grupo cine liberación) es que hay una empatía entre estéticas que se valen de la acción como un recurso fundamental en la construcción de su objeto artístico (Oubiña, 2016). La primera obra de arte de los medios de comunicación de 1966, en la que participa, pero sobre todo a partir de la cual reflexiona e incorpora una nueva estética, quien será el principal promotor de Sobre, Roberto Jacoby, es el momento de ruptura estético fundamental para entender este proceso de radicalización estético político que de algún modo culmina colectivamente en Tucumán Arde, y como intento de continuidad sin el grupo anterior, en la revista Sobre.

\section{III}

La primera obra de arte de los medios de comunicación abandona radicalmente los materiales convencionales como la tela y el pincel, y no es que los reemplaza por materiales cotidianos, de valor menor, como podría ser la experiencia que con el collage realizará Antonio Berni. Los recursos son, como los llamaron en el momento recurriendo a una cita del vanguardista ruso El Lissitzky, inmateriales (Lissitzky, 1967). "Después del pop nosotros desmaterializamos", decía Oscar Masotta (Masotta, 1967). El hecho artístico en cuestión consistió en lo siguiente: estos artistas jóvenes informaron a diarios y revistas con detalles de lugares, nombres, momento y registros fotográficos, la existencia de un happening que no había ocurrido. Los murmullos sociales y los artículos de los medios construyeron un hecho a partir de esas acciones. Un hecho construido por los medios y los murmullos sociales: una obra procesual, que habilitó a referir, a comentar y a discutir, sobre un hecho puntual que no existió. Aunque lo que efectivamente existió fueron las gacetillas de prensa y los comentarios inclusive de aquellos que mencionaban haber estado en el lugar.

Esta obra producía también de hecho una situación que cuestionaba las formas de exhibición y circulación del arte, la misma institucionalidad artística. Cosa que no ocurría con la literatura en un momento en que los 
autores latinoamericanos protagonistas del llamado boom latinoamericano producían innovaciones estéticas y portaban miradas radicalizadas políticamente, pero se valían de, y eran bien recibidos por, una industria editorial que lograba con esos productos extraordinarios éxitos económicos. Del mismo modo, las obras del nuevo cine latinoamericano, como La hora de los hornos, encontrarán una gran recepción en los festivales internacionales de cine y, por lo tanto, aunque tuviesen formas de circulación alternativa en el país, por el mundo marchaban por carriles convencionales de una zona sensibilizada por la radicalización política de la industria cinematográfica (Oubiña, 2016).

Pero esta ruptura en los materiales suponía además propuestas que desacomodaban lo trivial, lo consabido, lo legítimo. Mirada que no resulta extraña a las experiencias de las vanguardias de principios del siglo XX y que proponían al hecho artístico como un objeto de conocimiento y con potencialidad política. Y a la voluntad de desacomodamiento de sentidos comunes se agrega en este caso, la posibilidad de imaginar al receptor en acción como consecuencia de esa relación. Las lecturas del lingüista Roman Jakobson y de Mac Luhan, le dan a Jacoby el argumento para politizar un tipo de proceso sobre el que ya había trabajado la vanguardia soviética: la publicidad, la propaganda (Jacoby, Costa, 1967). Pero en este caso no se trata de propaganda. No tiene el objetivo de conseguir la aceptación en los receptores de un programa de la revolución o de una acción específica que conviene a la revolución. En este caso la politización está en la capacidad desacomodadora de la obra (Rubinich, 2007), en su potencialidad para problematizar convenciones artísticas o sociales más generales, que permiten generar reflexiones e incidir en las prácticas sociales concretas.

El objetivo explícito de esta estética, dicho en términos que usaba Jacoby en 1967, "es actuar sobre el receptor: hacer hacer." (Jacoby, Costa, 1967) Pero el hacer hacer, no como parte de un programa de educación de las masas en el sentido de la subordinación a consignas, sino como una propuesta de desarropamiento de lo viejo que, coincidiendo con la efervescencia social y en una situación de confrontación clara con diversas doxas, adquiere una significación política de una gran potencia simbólica.

Esta obra resulta central para dar cuenta del proceso de radicalización estética de jóvenes artistas que, participando de los nuevos aires de la modernidad artística tanto en Buenos Aires como en la ciudad de Rosario, se rebelarán contra las formas convencionales que entendían adoptaba esa modernidad, y contra sus instituciones (centralmente el Instituto Di Tella) y sus animadores y organizadores, como Jorge Romero Brest. Fruto de esa inconformidad resulta la experiencia de arte colectivo Tucumán Arde, que encontrará contención fuera de las instituciones convencionales del mundo del arte, específicamente en un espacio significativo de la cultura de la nueva izquierda que es la CGT de los Argentinos.

Tucumán Arde (Longoni, Mestman,2008) es una experiencia compleja compuesta por distintas acciones ocurridas entre mediados de setiembre (el primero de los viajes de un grupo de artistas a Tucumán), y fines de noviembre de 1968, cuando se clausura la muestra posterior a la primera realizada en Rosario, en el local de la CGTA de Buenos Aires. Esta experiencia artística despliega sus materiales constructivos sobre dos cuestiones centrales de la realidad de la época: 1) la situación de crisis social de la provincia argentina de Tucumán y 2) la ignorancia de esta crisis en el debate público constreñido por un gobierno de dictadura militar. El objeto construido, es un proceso con múltiples y diversos elementos (desde conferencias de prensa que son verdaderas performances, hasta estrategias de imposición de un nombre y dos muestras en un sentido más o menos convencional) extendidos en un tiempo de dos meses y medio aproximadamente, en el que confluyen las nuevas formas de arte llamado inmaterial concebido como apuestas de problematización de sentidos comunes y por lo tanto de conocimiento que es la forma experimental reflexiva de enlazar la corriente modernizadora, con los proceso de radicalización política.

De Tucumán Arde participaron más de treinta artistas, y también unos pocos intelectuales de las ciencias sociales y humanas, todos fundamentalmente ligados a nuevas y prestigiosas redes culturales más o menos informales de las ciudades de Rosario y Buenos Aires (Longoni, Mestman,2008).

El tono de Tucumán arde es un llamado a la acción construido con pertrechos de las formas más radicales del proceso de modernización del campo artístico. $Y$ va a producir un salto cualitativo porque se incorpora 
la dimensión política de una manera densa, produciendo un objeto estético singular que cambia las reglas del juego de la relación arte y política, inhibiendo la cita política como recurso retórico y llamando a poner manos a la obra sin abandonar la especificidad artística. Esto último le otorga una potencia dramática muy especial porque no se está interviniendo desde una galería neoyorquina, sino desde un continente que ha desplegado las armas de la razón de una manera extraordinariamente productiva, pero también las de la pasión, lo que supone implicarse en un proyecto de vida que en todas sus dimensiones confronta con las formas de la sociedad leídas como distintas manifestaciones de un sistema de opresión.

Este gran paso adelante entonces produce en el momento, un desacomodamiento en las zonas del campo cultural sensibilizadas de algún u otro modo con la posibilidad de la empatía entre radicalidad estética y radicalidad política. No obstante, esta es una acción artística que no encuentra narradores inmediatos porque en esta forma hay un problema, ya que no es sólo la adhesión a una concepción de cambio social radical, produciendo nuevas estéticas más o menos compatibles con ese ideal, sino que es una propuesta en la que la realización de esa estética implica un cambio en las formas de producción, circulación y consumo de la obra de arte.

Y, en verdad la sensibilización política en distintas zonas del campo cultural no se propone producir transformaciones inmediatas sobre el papel del artista, ni sobre los medios de producción y difusión de su obra. El artista, desde su lugar de autoridad cultural, puede adherir o más intensamente profetizar sobre las bondades de nuevas experiencias políticas y denunciar situaciones que en los hechos atenten contra ese ideal. Eso no sólo no modifica, sino que refuerza el papel del intelectual consolidado a fines del siglo XIX. Las experiencias de la literatura latinoamericana nombradas como el boom, por lo menos hasta el año 68 o 69 contaban con figuras relevantes adherentes a los procesos revolucionarios. La literatura del boom producía una singularidad que entusiasmaba a los mundos culturales desarrollados. El exotismo del mundo latinoamericano, con sus tiempos circulares, con sus prácticas desacomodadoras de la racionalidad occidental se construía con las herramientas más avanzadas de esa racionalidad: las herramientas de las vanguardias literarias. El boom además se constituía en un gran negocio editorial y la figura del escritor, por más que existiesen debates sobre la implicación directa en los procesos revolucionarios, era la figura clásica del profeta investido de autoridad. En los hechos Carpentier es una figura clásica, como también lo es Roa Bastos, y también los más jóvenes Vargas Llosa, Fuentes y García Márquez. Están en un podio que la cultura occidental erigió ante el saludo al avance del progreso y el papel que en este proceso le cabía a la ciencia y la cultura.

Tucumán Arde, por el contrario, problematiza no sólo la organización social y política de la sociedad, sino que arremete en su realización, contra los altares tradicionales, que objetivamente con su autoridad contribuían a legitimar esos procesos, y además, bajo esas formas convencionales construía algo que parecía ser una estética singular en el caso de la literatura. El llamado a la acción podía ser recepcionado en la disposición a la práctica política a la específica lucha revolucionaria, pero en términos políticos más generales eran muy pocos los que imaginaban que podía generalizarse una propuesta que implicaba la descalificación de instituciones tradicionales de la cultura, sobre todo porque podían también servir de tribuna a la lucha revolucionaria.

Tucumán Arde es una propuesta que, mejor o peor, intenta adelantar el tiempo y realizar en el presente, algo parecido a formas del arte que existirán en la nueva sociedad. Las condiciones para recepcionar el llamado a la acción que se desprendían de la experiencia cubana y de los revolucionarios ejemplares, existían en la política y de hecho en muchos lugares de América Latina. En Argentina en particular la acción insurgente comienza a tornarse relevante para la política. En el mundo del arte se podían producir simpatías y adhesiones sin que esto implicase un cambio en el papel tradicional del intelectual que desde su lugar prestigiado por el conjunto de la sociedad y desde la autoridad de su obra que logra ese mismo reconocimiento, bendice y reprueba. Pero ocurrió que había una experiencia que si podía escuchar ese llamado porque lograba una profunda identificación estético conceptual con un llamado a la acción que más que asentarse en proclamas políticas se expresaba en vivencias intensas. Era el encuentro de una estética que en los hechos descalificaba 
las formas existentes del arte y alentaba vivencias que desafiaban el orden político y económico. El encuentro entre el arte transformador y la vida transformadora.

El rechazo a las formas organizacionales y productivas de la sociedad del presente implica imaginar otras formas de producción económica, de organización política y social y también nuevas formas de producir una obra de arte y de relacionar esa obra con la sociedad. El arte construido por un colectivo en el que no participan exclusivamente los agentes que hoy se llaman artistas y que interviene reflexivamente, sin disolverse en el discurso político, en las luchas por la imposición de visiones del mundo. El arte que no renuncia a su especificidad, porque no es un informe científico, sino un objeto artístico, como una de las formas de producción de conocimiento. Este gesto supone, ya no la confrontación con las instituciones convencionales del arte sino la intervención con nuevas formas en distintos espacios de la sociedad. Lo que se está haciendo es prefigurar un nuevo modo de producción artístico, se anticipa el nuevo mundo. No hay que esperar a la llegada del mundo nuevo, se puede experimentar el mundo nuevo en el proceso de lucha.

La implicación con la acción, el "hacer hacer", se correspondía con lo que unos años antes se planteaba en las nuevas obras de los medios de comunicación de masas explícitamente, pero se potenciaba porque la frase de Octavio Paz, "se acabó la contemplación estética", se relacionaba estrechamente, más allá de las voluntades individuales del que la pronunció y de quienes la repetían, con una situación de "tomar al toro por las astas" de la mano de referencias políticas latinoamericanas que en verdad eran potentes referencias morales.

Cuando Ernesto Guevara en su intervención en Naciones Unidas en 1964 es interpelado irónicamente por un delegado de una dictadura latinoamericana sobre sus distintos acentos y su confusa identidad nacional reafirma allí su condición de patriota latinoamericano y su compromiso extremo con la liberación de cualquiera de esos países, sin pedir nada a cambio. Afirmará entonces algo que en su voz se convierte en un llamado que conmoverá mucho más que las lecturas optimistas sobre las posibilidades del marxismo y la revolución. Dirá que tanto él como el entero pueblo de Cuba son fieles al apotegma maravilloso de Martí: que todo ser humano verdadero debe sentir en la mejilla el golpe dado a cualquier mejilla de ser humano.

Es que las referencias morales que llamaban a la implicación en la lucha contra la injusticia en América Latina no eran retóricas y no surgían de submundos marginales. En 1965, nuevamente Ernesto Guevara, comandante y funcionario importante de la República de Cuba, produce un gesto que tendrá una gran significación a nivel internacional. Guevara renunciaba a todos sus cargos y a la nacionalidad cubana para dedicarse a luchar por cambiar drásticamente las formas de vida, para apostar por la revolución en distintos lugares del mundo. En su carta de despedida de Cuba es que escribe la frase que ligada a sus acciones de renunciamiento conmoverá a las juventudes sensibles e informadas del mundo: Hasta la victoria siempre.

A principios de 1966 morirá en la selva colombiana como combatiente del Ejército de liberación Nacional, Camilo Torres Restrepo. Camilo Torres era un joven de clase acomodada de la ciudad de Bogotá, que fundará junto a Orlando Fals Borda la Carrera de Sociología en 1960, pero que además y con especial significación para el continente, era un sacerdote católico implicado fuertemente en la lucha de las poblaciones oprimidas de su país y que había llevado esa implicación a la máxima expresión optando por la lucha armada. Raymundo Ongaro, el secretario general de la CGTA, que habló en la inauguración de Tucumán Arde en Buenos Aires, era percibido por los trabajadores afiliados a esa central -quizás como muchos de los dirigentes combativos-, no sólo como un dirigente respetado en tanto tal, sino como una figura moral que no separaba el decir del hacer en las distintas dimensiones de la vida (semanario CGT N 31, 1968, Longoni, 2014)

Las acciones del Che, como lo demostraba el recientemente publicado Diario de Bolivia que se convertiría en un best seller internacional, eran también un catecismo de una nueva moral. No se trataba simplemente de una lucha armada contra un poder, las acciones que relataba ese diario eran la expresión de la moral del hombre nuevo. El trato a los prisioneros, la relación con sus subordinados militares, su austeridad como jefe, y como se conocerá por rumores y será confirmado luego, su valor comprensivo frente al soldado al que le han ordenado darle muerte. 
Tucumán Arde en ese contexto, más allá de las intenciones individuales de los distintos participantes, era una apuesta intensa porque en términos más evidentes, era una experiencia de lucha revolucionaria desde la especificidad del campo cultural, que además se hacía de algún modo anticipando las condiciones de relación arte sociedad que se darían en la sociedad futura. Como el Che, anticipaba formas distintas de relación entre los seres humanos, esta experiencia anunciaba en los hechos una nueva forma de arte.

Sin lugar a dudas esta experiencia era compatible con un entusiasmo circulante por el mundo político cultural que podía expresarse en la bandera de Octavio Paz: se acabó la contemplación estética porque la estética se disuelve en la vida social. Y eso suponía irrumpir en un museo al grito de Fuera yanquis de Vietnam, ser detenidos por la policía y afirmar como lo hacía el manifiesto que conformaba la obra de Roberto Jacoby, Mensaje en el Di Tella, luego de entrecomillar la frase de Paz: "Por eso se esparce por todas artes una lucha necesaria, sangrienta y hermosa por la creación del mundo nuevo. Y la vanguardia no puede dejar de afirmar la historia, de afirmar la justa, heroica violencia de esta lucha”. Los artistas de Rosario habían sostenido apenas unos meses antes: "declaramos que la vida del Che Guevara y la acción de los estudiantes franceses son obras de arte mayores que la mayoría de las paparruchadas colgadas en los miles de museos del mundo” (Longoni, 2014).

El año 1969 en Argentina es quizás un período en que la disposición colectiva a cuestionar el orden irá creciendo en distintos espacios de la sociedad, y manifestándose ahora en acciones colectivas concretas destinadas a confrontar con el orden político. Los artistas que reivindicaban como hecho estético el mayo francés y que llamaban a la acción se encontrarán ahora en el propio territorio con una rebelión en las calles intensa y significativa. La pregunta es qué hacer en ese contexto, pero sobre todo, desde dónde hacer. No se podía implementar nada desde las instituciones modernas descalificadas como el Instituto Di Tella y menos con los museos. La experiencia Tucumán arde en el local de la CGT de los argentinos de Buenos Aires es clausurada por la policía de la dictadura. A diferencia de los escritores y de los cineastas implicados en la radicalización política, este grupo que armó Tucumán Arde, se va a quedar sin soporte. El artista Pablo Suárez, que un año antes en la puerta del instituto Di Tella repartía una carta que entre otras cosas se preguntaba "A qué vienen los patrocinadores del Museo de arte moderno de Nueva York, sino a comprar conciencias y a prostituir a los artistas argentinos" (Longoni, 2014), deja la actividad artística; algo parecido va a ocurrir con Juan Pablo Rienzi; otro artista rosarino que participa de las experiencias rupturistas de 1968, Eduardo Favario, también del grupo de Rosario, se integrará al Ejército Revolucionario del Pueblo y morirá en combate unos años después. Roberto Jacoby y Beatriz Balvé, que habían participado de Tucumán Arde, comenzarán a colaborar en el CICSO en una investigación sobre el Cordobazo y otras revueltas populares que se publicará en 1973 bajo el título Lucha de calles lucha de clases (Balvé y otros, 2006).

En el marco del fluir de ese clima "desclasificador" en el que los sentidos del mundo social son puestos en cuestión (Bourdieu, 2008) es que la revista Sobre, en los hechos, se convierte en una apuesta por conformar un soporte que estas experiencias artísticas no encuentran justamente en los momentos en que esa lucha revolucionaria se despliega. Es una apuesta en la que, aun existiendo algunas formas clásicas del agit prop, la marca a fuego está, de distintas maneras, en una identidad estética clara implicada en las fuertes experiencias rupturistas de dos de las personas que conforman el grupo más visible de la revista: Roberto Jacoby y Octavio Getino. Es una apuesta en el caso específico de Jacoby, por insertar la experiencia hereje de la que él es un protagonista relevante en lo que se llamaban las artes plásticas, en una red de relaciones que permita legitimarla, junto a otra experiencia artística, como la del Grupo cine liberación que ya está obteniendo legitimidad internacional, y a otras dos zonas reflexivas del campo cultural implicadas en el proceso ya desencadenado de acción revolucionaria. 
Efectivamente en la revista Sobre se ensaya la posibilidad de relación con dos grupos de esta zona del campo cultural donde sectores de lo que efectivamente se conforma como una nueva izquierda se encuentran abocados a la reflexión para la acción. Uno con perfil más académico y el otro muy ligado a grupos que se están implicando decididamente en la lucha armada. El primero es el centro de investigación en ciencias sociales (CICSO), sociólogos provenientes de las distintas rupturas del Partido Socialista argentino que conforman este centro de investigación luego de la llamada Noche de los bastones largos que reprime y expulsa profesores de la Universidad de Buenos Aires (Santella 2000), y, por otro lado, a través de uno de los miembros de la revista, Antonio Caparrós- que potencialmente también habilita una relación con la Cuba revolucionaria-, con grupos que en esos momentos están conformando organizaciones político-militares que se los conoce ex post, como las proto Far (por Fuerzas Armadas Revolucionarias) que derivarán en las propias FAR y de algún modo también en los Comandos Populares de Liberación (CPL) (González Canosa, 2012).

La presencia de Caparrós, en términos de apertura de posibilidades hacia esa zona de nuevas generaciones de intelectuales y actores concretos ligados al germen de experiencias revolucionarias, y sobre todo a grupos que ya estaban dispuestos a la lucha armada, es muy importante. Jacoby sostiene que los números de Sobre se armaron en la cocina de Antonio Caparrós (Longoni, 2011). Caparrós era mayor que los otros integrantes (tenía en ese momento 41 años y Jacoby 25), era un profesional con trayectoria. Profesor de la Carrera de Psicología hasta 1966, había debatido con las posiciones pavlovianas sostenidas por los psiquiatras del Partido Comunista argentino, del que en 1963 se había alejado con otros sectores del campo cultural. Luego de esa ruptura Caparrós viaja en diversas oportunidades a Cuba y en términos culturales es muy relevante que haya sido el único argentino que participó, por decisión del Che Guevara que era Ministro de Industria de Cuba, en el debate sobre incentivos morales e incentivos materiales ${ }^{1}$. Esa relación de cercanía con la Cuba revolucionaria la utilizaría, entre otras cosas, para implicar a algunos jóvenes argentinos que se preparaban para seguir el camino del CHE. De hecho, en 1967 en el viaje que hace Caparrós a Cuba también va Carlos Olmedo y probablemente a través de las gestiones de Caparrós recibe entrenamiento militar. Olmedo, quien luego sería el comandante de las Fuerzas Armadas Revolucionarias y que seguramente unos días antes de la aparición de Sobre, habría participado como uno de los organizadores principales de la quema a los 13 supermercados Minimax con motivo de la visita de Nelson Rockefeller a la Argentina, se había contactado con Roberto Quieto, otro de los futuros jefes de esa organización, a través de Caparrós. En ese grupo de jóvenes que se relacionaban con Cuba a través de Caparrós también estaba otro que además de Olmedo tenía un perfil intelectual y que luego sería uno de los jefes guerrilleros de los Comandos Populares de Liberación: Oscar Terán (González Canosa, 2012).

Son maneras de enlazar a la revista cuya misma forma es una expresión de una mirada sostenida en una estética de la acción, con otras experiencias que desde el campo cultural se relacionan de distintas maneras con la acción revolucionaria. La revista es la concreción de la noción del "hacer hacer" en un objeto (objetos en realidad) que no se realizan como objetos estéticos hasta que alguien se vale de ellos; en este caso para contribuir a la acción revolucionaria: pasando de mano en mano alguno de los materiales, debatiendo en grupo a partir de ellos, intentando evitar que ni los documentos ni los afiches, sean objeto de una lectura "pasiva". Es la continuidad de la experiencia que incorpora nuevos materiales, tal el caso de los elementos "inmateriales" como las relaciones sociales, para pelear de manera clara y contundente con la noción de cultura fetiche, de cultura como objeto realizado, como opus operatum (Bourdieu, 2008), reivindicando la cultura como instrumento creativo de la acción humana, la cultura en tanto modus operandi. En realidad, la cosa, el objeto estético, se realiza en el modus operandi. El opus operatum de algún modo es el proceso social que es totalizado, o bien aproximadamente totalizado, ex post. Como dirán los analistas y reafirmará retrospectivamente uno de los protagonistas (Jacoby, en Longoni, 2011), Sobre es "una antirrevista". Se trata como se ha dicho de un sobre de papel madera que en el frente tiene impreso en mimeógrafo el título, el número, sin fecha, y el índice en letra de imprenta manuscrita. Al dorso, también mimeografiado, un breve 
manifiesto. Adentro del sobre está el material mimeografiado que incluye, además de los documentos escritos, en el N1 tres afiches serigrafiados, y sólo uno en el N2.

Y si bien la realización de esta antirrevista es la continuidad de una perspectiva estética que generó reflexiones teóricas de los propios hacedores y se manifestó en obras en distintos espacios del mundo de la cultura, en ese 1969 adquiere un sentido, sino otro, al menos de distinta intensidad, que es sin lugar a dudas mayor en términos vitales, y de algún modo dramático. La manera en que se expresa discursivamente esta reivindicación de la cultura como acción contra la cultura cosa, está en el manifiesto del dorso del sobre. “/Si al cabo de una semana SOBRE está intacto/Y usted no ha discutido, no ha pensado, no se ha reunido/PARA HACER ALGO/Es que no ha sabido usarlo".

Esto dicho apenas un año antes hubiese sido portador de otros sentidos. Es que una acción de este tipo, o cualquiera de las realizadas en el 68 por los artistas rebeldes del campo de las artes plásticas, tenía un objetivo que era la pelea contra la estabilización de la vanguardia que intentaba la posición expresada sintéticamente en el gran armador que era Jorge Romero Brest. Esa pelea pese a su alto sentido herético era contenida en los espacios del mundo del arte. De distintos modos se confrontaba con la modernidad artística porque esa apuesta era innovadora en el marco de una institucionalidad que desde esta perspectiva se veía como opresiva para las obras de nuevo tipo que surgían de esta experiencia transformadora. En este momento, en 1969, esa batalla ya está dada, y hay otras que sobrevienen.

Claro, se había generado una posición que reivindicaba la experiencia de habilitación de nuevos materiales no como una experimentación que se desatiende del mundo que no sea el propio, sino que se anunciaba una implicación con el mundo, una problematización del arte que implicaba una problematización de la entera sociedad y en ello la propia institucionalidad y las reglas del juego.

Ahora había que continuar y afianzarla: enlazar la sensibilidad que problematiza el arte, con la sensibilidad política que ahora en 1969 no solo problematiza el mundo sino que decididamente confronta, se alza contra él. Si el año anterior se había confrontado con el arte nuevo "convencional", que no pretendía sino recorrer los caminos- también los nuevos-, trazados por las redes instituciones y grupos del campo artístico, ahora se interpelaba a los espacios más innovadores del campo cultural para que de distintos modos se incluyeran (y los incluyeran) en el fluir más vivo de una cultura que había reconocido a esta como la hora de la acción.

En 1969 en Buenos Aires, cada uno de los grupos del mundo cultural sensibilizados por el Cordobazo, podía hacer suya la tesis 11 sobre Feuerbach, de Marx ("Los filósofos no han hecho más que interpretar de diversos modos el mundo, pero de lo que se trata es de transformarlo.") (Marx 1959). Y ahora no de un modo retórico en un trasnochado debate entre diletantes, sino como un aliento para la acción revolucionaria que se percibía irremediable.

Quizás la manera más clara de expresión artística de este clima es el afiche realizado por Roberto Jacoby que es parte de los elementos que conforman la revista. El afiche en rojo tiene en la parte superior en blanco y negro, la clásica imagen de Ernesto Che Guevara con boina negra mirando a lo lejos, resultado de la fotografía tomada en 1960 por Alberto Díaz (Korda), y abajo, ocupando la mitad del afiche en letras mayúsculas la frase "Un guerrillero no muere para que se lo cuelgue en la pared" (Sobre 1969).

\section{REFERENCIAS}

Balvé, B.; Murmis, M.; Marín, J. C.; Aufgang, L.; Bar, T., Balvé B., Jacoby, R., Jacob, G., (2006). Lucha de calles. Lucha de clases, Buenos Aires: Ediciones Razón y Revolución.

Bourdieu, P, (1995). Las reglas del arte. Génesis y estructura del campo literario, Barcelona: Anagrama.

Bourdieu, P, (2008). Homo academicus, Buenos Aires: SXXI

Castro, V (2018). "SOBRE la cultura de la liberación. Introducción", AMÉRICALEE. El portal de publicaciones latinoamericanas del siglo XX. ISSN: 2545-823X. recuperado en http://americalee.cedinci.org/portfolio-item s/sobre-la-cultura-de-la-liberacion/ 
Giunta, A. (2004). Vanguardia, internacionalismo y politica. Buenos Aires: Siglo XXI editores.

González Canosa, M. (2012). Modelo para armar: itinerarios y ámbitos disidentes del Partido Comunista Argentino en la gestación de uno de los grupos fundadores de las Fuerzas Armadas Revolucionarias (1960-1967), recuperado en www.izquierdas.cl, 12, abril 2012, ISSN 0718-5049, pp.111-142

Jozami, E. (2006). Rodolfo Walsh. La palabra y la acción. Buenos Aires: Norma.

Jacoby, R. (2014). El asalto al cielo. Formación de la teoria revolucionaria, desde la comuna de 1871 a Octubre de 1917, Buenos Aires: Mansalva.

Jacoby, R., y Costa, E. (1967). Un arte de lo medios de comunicación, en Masotta, O., (1967) (comp.), Happenings, Buenos Aires: Jorge Alvarez.

Jacoby, R. y Di Paola, J. (2003). Moncada, Buenos Aires: Adriana Hidalgo

King, J. (2009). El Di Tella y el desarrollo cultural argentino en la década del sesenta. Buenos Aires: Asunto impreso ediciones.

Lissitzky, E. (1967). The Future of the Book, New Left Review, enero/febrero 1967

Longoni, A., y Mestman, M., (2008). Del Di Tella a "Tucumán Arde". Vanguardia artística y política en el 68 argentino, Buenos Aires: EUDEBA.

Longoni, A. (editora). (2011). El deseo nace del derrumbe. Roberto Jacoby. Acciones, conceptos escritos, Barcelona, Buenos Aires: Ediciones la central Adriana Hidalgo, museo nacional centro de arte reina Sofía, Red conceptualismo del sur,

Longoni, A. (2014). Vanguardia y revolución, Buenos Aires: Ariel.

Masotta, O. (1967). El pop art, Buenos Aires: Columba.

Masotta, O. (comp.) (1967). Happenings, Buenos Aires: Jorge Alvarez.

Masotta, O. (1969). Conciencia y estructura, Buenos Aires: Jorge Alvarez

Masotta, O. (2004). Revolución en el arte, Barcelona: Edhasa.

Mannheim, K. (1987). Ideología y utopía, México: Fondo de Cultura Económica.

Mannheim, K. (1963). Ensayos de sociología de la cultura, Madrid: Aguilar

Marín, J. C. ( 2007). Los hechos armados, Argentina 1973-1976. Acumulación primaria del genocidio, Buenos Aires: La rosa blindada/PICASO,

Marx, K., (1959). Tesis sobre Feuerbach. En Marx y Engels “La ideología alemana”. Montevideo: Ediciones Pueblos Unidos.

Oubiña, D. (2016). El fin de lo nuevo (cineastas, autores, Argentina, 1969), Cuadernos LIRICO [En línea],15. Recuperado en URL : http:// lirico.revues.org/2980 ; DOI : v10.4000/lirico.2980

Rubinich, L. (2009). Reinventar el fuego Construcción de relaciones de fuerza simbólica y radicalidad en la estética de Roberto Jacoby. Apuntes de Investigación N 15

Rubinich, L. (2007). Apuntes sobre la politicidad del arte, Ramona N 73,

Sarlo B. (2006). La estética de las buenas causas, Punto de Vista N 85 mes de agosto,.

Santella, A. (2000). Desarrollos en ciencias sociales. El CICSO, Dossier: CICSO: Marxismo, Historia y Ciencias Sociales en la Argentina, Buenos Aires. Razón y Revolución N6, otoño de 2000.

Shklovski, V. (1980). El arte como artificio. En Todorov, T., Teoría de la literatura de losformalistas rusos, México: FCE

Sobre la cultura de la liberación, Archivo digital Americalee CEDINCI, Buenos Aires http://americalee.cedinci.org/ portfolio-items/sobre-la-cultura-de-la-liberacion/

Williams, R. (2000). Marxismo y literatura, Barcelona; Península. 


\section{Notas}

1 En la revista "Nuestra industria económica" del Ministerio de Industria de Cuba, Guevara había abierto el juego para que los distintos contendientes manifestasen sus posiciones públicamente acerca de lo que era un problema concreto de la economía cubana, pero que también tenía trascendencia filosófico-política. Allí, y en otros medios, los años anteriores habían intervenido argumentando sobre cada una de los posiciones, funcionarios cubanos e intelectuales extranjeros, Principalmente el francés Charles Betetelheim y en posición cercana al Che, el belga Ernest Mandel. En el $\mathrm{N}^{\circ} 15$ de esa revista, junto a un artículo del Che que se había publicado en la revista Marcha de Montevideo, en marzo de ese año (El socialismo y el hombre en Cuba), se publica uno de un joven colaborador del equipo del Che que tenía una posición contraría, Alberto Mora, otro de Ernest Mandel, y el trabajo "Incentivos morales y materiales en el trabajo", de Antonio Caparrós. 